\title{
PEDIATRIC ORIGINAL ARTICLE Body mass index adjustments to increase the validity of body fatness assessment in UK Black African and South Asian children
}

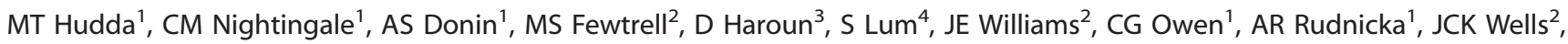 \\ DG Cook ${ }^{1}$ and PH Whincup ${ }^{1}$
}

BACKGROUND/OBJECTIVES: Body mass index (BMI) (weight per height ${ }^{2}$ ) is the most widely used marker of childhood obesity and total body fatness (BF). However, its validity is limited, especially in children of South Asian and Black African origins. We aimed to quantify BMI adjustments needed for UK children of Black African and South Asian origins so that adjusted BMI related to BF in the same way as for White European children.

METHODS: We used data from four recent UK studies that made deuterium dilution BF measurements in UK children of White European, South Asian and Black African origins. A height-standardized fat mass index (FMI) was derived to represent BF. Linear regression models were then fitted, separately for boys and girls, to quantify ethnic differences in BMI-FMI relationships and to provide ethnic-specific BMI adjustments.

RESULTS: We restricted analyses to 4-12 year olds, to whom a single consistent FMI (fat mass per height ${ }^{5}$ ) could be applied. BMI consistently underestimated BF in South Asians, requiring positive BMI adjustments of $+1.12 \mathrm{~kg} \mathrm{~m}^{-2}$ (95\% confidence interval $(\mathrm{Cl})$ : $\left.0.83,1.41 \mathrm{~kg} \mathrm{~m}^{-2} ; P<0.0001\right)$ for boys and $+1.07 \mathrm{~kg} \mathrm{~m}^{-2}\left(95 \% \mathrm{Cl}: 0.74,1.39 \mathrm{~kg} \mathrm{~m}^{-2} ; P<0.0001\right)$ for girls of all age groups and FMI levels. BMI overestimated BF in Black Africans, requiring negative BMI adjustments for Black African children. However, these were complex because there were statistically significant interactions between Black African ethnicity and FMI ( $P=0.004$ boys; $P=0.003$ girls) and also between FMI and age group $(P<0.0001$ for boys and girls). BMI adjustments therefore varied by age group and FMI level (and indirectly BMI); the largest adjustments were in younger children with higher unadjusted BMI and the smallest in older children with lower unadjusted BMI.

CONCLUSIONS: BMI underestimated BF in South Asians and overestimated BF in Black Africans. Ethnic-specific adjustments, increasing BMI in South Asians and reducing BMI in Black Africans, can improve the accuracy of BF assessment in these children.

International Journal of Obesity (2017) 41, 1048-1055; doi:10.1038/ijo.2017.75

\section{INTRODUCTION}

Overweight and obesity in UK children represent a major public health challenge, ${ }^{1}$ with both short- and long-term consequences for physical and mental health. ${ }^{2-5}$ Accurate assessment of total BF is critical for effective surveillance, prevention, diagnosis and management of this problem. ${ }^{6}$ Body mass index (BMI) (weight per height ${ }^{2}$ ) is the most widely used marker of obesity and total BF in children as well as adults, providing the basis for most widely used definitions of childhood overweight and obesity. ${ }^{7,8}$ However, the validity of BMI as a marker of childhood total BF is limited, ${ }^{9}$ particularly in UK South Asian and Black African ethnic minority populations. BMI systematically underestimates total BF in UK South Asian children ${ }^{10,11}$ and systematically overestimates total BF in UK Black African children. ${ }^{10,11}$ These errors are a cause for concern in both ethnic groups but especially in UK South Asian children, who have a higher burden of total BF and obesity, ${ }^{10,11}$ greater metabolic sensitivity to the effects of $\mathrm{BF}^{12,13}$ and high long-term risks of complications of increased $\mathrm{BF}$, particularly type 2 diabetes and cardiovascular disease. ${ }^{14,15}$
The errors in the measurement of BMI could potentially be addressed by adjusting BMI for ethnicity, ${ }^{16}$ so that adjusted BMI values have the same relationship to total $B F$ as in White Europeans. ${ }^{11}$ We have therefore pooled data from four studies that used the deuterium dilution method to make accurate measurements of body water-and indirectly of fat-free mass (FFM) and fat mass (FM) - in UK boys and girls of White European, South Asian and Black African origins aged 4-15 years. These data were used to quantify the BMI adjustments needed for South Asian and Black African children, to ensure that adjusted BMI values had the same relationship to total BF (expressed as a fat mass index (FMI)) as in White Europeans. ${ }^{11}$

\section{MATERIALS AND METHODS}

Data sources

Data from four recent studies, which used the deuterium dilution method to measure total body water (TBW; and indirectly FM) in population-based samples of UK children aged between 4 and 15 years, were obtained and pooled for analysis. Details of these studies and their participants are

'Population Health Research Institute, St George's, University of London, London, UK; ${ }^{2}$ Childhood Nutrition Research Centre, Population, Policy and Practice Programme, UCL Great Ormond Street Institute of Child Health, London, UK; ${ }^{3}$ College of Sustainability Sciences and Humanities, Department of Natural Science and Public Health, Zayed University, Dubai, UAE and ${ }^{4}$ Respiratory, Critical Care and Anaesthesia section of III Programme (Portex Unit), UCL Great Ormond Street Institute of Child Health, London, UK. Correspondence: Professor PH Whincup, Population Health Research Institute, St George's, University of London, Cranmer Terrace, London SW17 ORE, UK. 
provided in Supplementary Tables S1 and S2. Three of the four studies were carried out during the past 10 years and were primarily populationbased studies based in primary or secondary schools, including approximately equal numbers of children of White European, South Asian and Black African origin; ${ }^{11,17,18}$ a small number of individuals in the ELBI study ${ }^{17}$ who were recruited from an obesity clinic $(n=19)$ were excluded from analysis. The fourth study, conducted over several years, predominantly included White European volunteers recruited by advertisement. ${ }^{19}$ Ethnicity was based on a combination of self-reported parental information on parental ethnicity ${ }^{11}$ and child ethnicity, ${ }^{11,18,19}$ with self-reported participant information on ethnicity for older children, ${ }^{17,19}$ using ethnic group categories based on the 2001 UK Census. For the present analyses, child ethnicity was categorized as White European, Black African (including both African and Caribbean descent), South Asian (including Indian, Pakistani, Bangladeshi and Sri Lankan descent), other ethnic group (including mixed ethnicity) and unknown ethnic group.

In all four studies, participants had standardized measurements of height and weight and TBW measured using the deuterium dilution method. They received standard deuterium oxide dosages and saliva samples were obtained for deuterium measurement at baseline and between 4 and $5 \mathrm{~h}$ postdose; participants avoided food and drink for at least 30 mins before each sample. All fluid consumption between the deuterium dose and the second saliva sample was documented. Deuterium concentrations in each saliva sample and each individual deuterium dose were measured by isotope-ratio mass spectrometry. ${ }^{19}$ TBW was calculated incorporating a correction for the exchange of deuterium with non-aqueous hydroge ${ }^{20}$ and adjusting for fluid intake during the equilibrium period. FFM was calculated from TBW using assumed hydration of lean tissue; ${ }^{21} \mathrm{FM}$ was calculated as the difference between body weight and FFM.

\section{Statistical methods}

Standardizing fat mass for height. To investigate the relationship between $\mathrm{BMI}$ and total $\mathrm{BF}$, it was first necessary to derive a height-independent FMI. To assess accurately the height power needed, log-transformed FM (dependent variable) was regressed on log-transformed height (independent variable), ${ }^{22}$ adjusting for sex and age in 1-year age groups. We then investigated whether the height power varied by age, ethnicity or sex by fitting two-way interaction terms between log height and these covariates. An interaction term for log height with age (in 1-year intervals) was included first and its statistical significance was assessed by means of a likelihood ratio test, followed by fitting of an interaction term for log height with ethnicity (interactions for South Asians and Black Africans were evaluated separately) and finally for log height with sex. Statistical significance was set at the $5 \%$ significance level for all likelihood ratio tests. In sensitivity analyses, models were stratified by sex and the above model building procedure was repeated.

Regression models relating body mass index and FMI. Regression models, stratified by sex, were used to quantify the ethnic differences in BMI-FMI relationships. BMI was regressed against FMI with additional covariates for ethnic group and age. Age was fitted in three prespecified 3-year groups (4.0-6.9, 7.0-9.9 and 10.0-12.9 years) to provide robust and stable agespecific estimates by sex, ensuring that all potentially pubertal children would be in the third group. Examination of the data suggested that the use of these 3-year age groups accounted for age effects adequately without a need for finer age divisions. All two-way interaction terms between FMl, ethnicity and age groups were included in the model using a stepwise forwards approach ${ }^{23}$ and three way interactions were only considered if their corresponding two-way interactions were statistically significant. The statistical significance of each interaction term was tested using the likelihood ratio test at the $5 \%$ significance level. All statistically significant interactions were included in the model, and model fit was checked by assessing residual plots and measures of $R^{2}$ gave an indication of the amount of variation explained by the model. These regression models were used to construct plots of BMI against FMI in each ethnic group by the 3-year age categories for boys and girls, to demonstrate ethnic differences in the BMI-FMI relationships. Finally, the ethnicity adjustments for each age and sex group were derived from the best-fitting regression model coefficients (as explained in detail in Supplementary Appendix 1). A summary of adjusted BMI values for unadjusted BMI values between 13 and $25 \mathrm{~kg} \mathrm{~m}^{-2}$ (5th to 95th BMI centiles for the 4-12-year-old study population) is presented (Table 1), together with full tabulations of adjusted $\mathrm{BMI}$ values and of adjustment factors for each $0.1 \mathrm{~kg} \mathrm{~m}^{-2} \mathrm{BMI}$
Table 1. Unadjusted and adjusted BMI values for UK Black African and South Asian children by sex and age group

\begin{tabular}{|c|c|c|c|c|c|c|}
\hline \multirow[t]{3}{*}{$B M I\left(k g ~ m^{-2}\right)$} & \multicolumn{3}{|c|}{ Boys } & \multicolumn{3}{|c|}{ Girls } \\
\hline & \multicolumn{3}{|c|}{ Adjusted BMI $\left(\mathrm{kg} \mathrm{m}^{-2}\right)$} & \multicolumn{3}{|c|}{ Adjusted BMI $\left(\mathrm{kg} \mathrm{m}^{-2}\right)$} \\
\hline & $\begin{array}{c}4-6 \\
\text { years }\end{array}$ & $\begin{array}{c}7-9 \\
\text { years }\end{array}$ & $\begin{array}{l}10-12 \\
\text { years }\end{array}$ & $\begin{array}{c}4-6 \\
\text { years }\end{array}$ & $\begin{array}{c}7-9 \\
\text { years }\end{array}$ & $\begin{array}{l}10-12 \\
\text { years }\end{array}$ \\
\hline \multicolumn{7}{|l|}{ Black Africans } \\
\hline 13.0 & 12.57 & 12.54 & 12.75 & 12.51 & 12.51 & 12.77 \\
\hline 14.0 & 13.36 & 13.40 & 13.63 & 13.32 & 13.38 & 13.66 \\
\hline 15.0 & 14.14 & 14.27 & 14.51 & 14.13 & 14.26 & 14.55 \\
\hline 16.0 & 14.93 & 15.13 & 15.39 & 14.94 & 15.14 & 15.44 \\
\hline 17.0 & 15.72 & 15.99 & 16.26 & 15.75 & 16.01 & 16.33 \\
\hline 18.0 & 16.50 & 16.85 & 17.14 & 16.56 & 16.89 & 17.22 \\
\hline 19.0 & 17.29 & 17.72 & 18.02 & 17.37 & 17.77 & 18.11 \\
\hline 20.0 & 18.08 & 18.58 & 18.90 & 18.17 & 18.64 & 19.00 \\
\hline 21.0 & 18.87 & 19.44 & 19.78 & 18.98 & 19.52 & 19.88 \\
\hline 22.0 & 19.65 & 20.30 & 20.66 & 19.79 & 20.40 & 20.77 \\
\hline 23.0 & 20.44 & 21.17 & 21.54 & 20.60 & 21.28 & 21.66 \\
\hline 24.0 & 21.23 & 22.03 & 22.42 & 21.41 & 22.15 & 22.55 \\
\hline 25.0 & 22.02 & 22.89 & 23.29 & 22.22 & 23.03 & 23.44 \\
\hline \multicolumn{7}{|l|}{ South Asians } \\
\hline 13.0 & 14.12 & 14.12 & 14.12 & 14.07 & 14.07 & 14.07 \\
\hline 14.0 & 15.12 & 15.12 & 15.12 & 15.07 & 15.07 & 15.07 \\
\hline 15.0 & 16.12 & 16.12 & 16.12 & 16.07 & 16.07 & 16.07 \\
\hline 16.0 & 17.12 & 17.12 & 17.12 & 17.07 & 17.07 & 17.07 \\
\hline 17.0 & 18.12 & 18.12 & 18.12 & 18.07 & 18.07 & 18.07 \\
\hline 18.0 & 19.12 & 19.12 & 19.12 & 19.07 & 19.07 & 19.07 \\
\hline 19.0 & 20.12 & 20.12 & 20.12 & 20.07 & 20.07 & 20.07 \\
\hline 20.0 & 21.12 & 21.12 & 21.12 & 21.07 & 21.07 & 21.07 \\
\hline 21.0 & 22.12 & 22.12 & 22.12 & 22.07 & 22.07 & 22.07 \\
\hline 22.0 & 23.12 & 23.12 & 23.12 & 23.07 & 23.07 & 23.07 \\
\hline 23.0 & 24.12 & 24.12 & 24.12 & 24.07 & 24.07 & 24.07 \\
\hline 24.0 & 25.12 & 25.12 & 25.12 & 25.07 & 25.07 & 25.07 \\
\hline 25.0 & 26.12 & 26.12 & 26.12 & 26.07 & 26.07 & 26.07 \\
\hline
\end{tabular}

Abbreviation: BMI, body mass index. Adjusted BMI values based on coefficients from best-fitting regression models in Table 3 for $1 \mathrm{~kg} \mathrm{~m}^{-2}$ intervals between 13 and $25 \mathrm{~kg} \mathrm{~m}^{-2}$ (5th to 95th BMI centiles). For precise unadjusted and corresponding adjusted BMI at $0.1 \mathrm{~kg} \mathrm{~m}^{-2}$ increments across the full BMI range see Supplementary Table S5.

increment across the complete $\mathrm{BMI}$ range in this study population (12-36.9 $\mathrm{kg} \mathrm{m}^{-2}$; Supplementary Tables S3 and S4, respectively).

\section{RESULTS}

Table 2 shows mean (s.d.) height, weight, BMI, FM and FFM values for boys and girls within each age group from the combined data set. Mean levels of all variables increased with age group, for both boys and girls. Across age groups, girls had a greater average weight and FM than boys. Black African children were consistently taller, weighed more and had a higher FFM than other ethnic groups, except in the oldest girls. Slightly different patterns were observed for FM; Black African and South Asian children had higher FM than White Europeans of the same age group, with the exception of girls in the oldest age group. Histograms showing the distributions of BMI, weight, FM and FFM by sex and age groups are presented in Supplementary Figure S1.

\section{Standardizing fat mass for height}

Based on a model regressing log FM on log height, age groups, sex and ethnicity, the age-specific height powers providing a height-independent FMI for both sexes combined are presented 
Table 2. Anthropometric and adiposity measures in children 4-15 years by sex, ethnicity and 3-year age groups

\begin{tabular}{|c|c|c|c|c|c|c|}
\hline & \multicolumn{3}{|c|}{ Boys } & \multicolumn{3}{|c|}{ Girls } \\
\hline & White European & Black African & South Asian & White European & Black African & South Asian \\
\hline$N$ & 38 & 21 & 19 & 44 & 23 & 17 \\
\hline Height $(\mathrm{cm})$ & $115.8(7.2)$ & $122.2(7.8)$ & $116.8(6.3)$ & $116.4(6.2)$ & $120.9(6.1)$ & $117.2(6.0)$ \\
\hline Weight $(\mathrm{kg})$ & $21.9(4.5)$ & $25.8(6.6)$ & $21.1(4.6)$ & $22.2(4.2)$ & $24.4(4.4)$ & $22.7(5.6)$ \\
\hline Body mass index $\left(\mathrm{kg} \mathrm{m}^{-2}\right)$ & $16.2(1.8)$ & $17.1(2.8)$ & $15.4(2.4)$ & $16.2(2.1)$ & $16.6(2.3)$ & $16.4(2.9)$ \\
\hline \multicolumn{7}{|l|}{$7-9$ years } \\
\hline$N$ & 205 & 146 & 179 & 209 & 173 & 170 \\
\hline Height $(\mathrm{cm})$ & $134.1(7.0)$ & $137.8(7.6)$ & $134.2(7.2)$ & $132.9(6.8)$ & $137.9(7.4)$ & $133.6(7.5)$ \\
\hline Weight $(\mathrm{kg})$ & $30.4(6.4)$ & $35.6(9.0)$ & $31.8(7.9)$ & $31.3(7.2)$ & $36.9(10.9)$ & $31.4(8.7)$ \\
\hline Body mass index $\left(\mathrm{kg} \mathrm{m}^{-2}\right)$ & $16.8(2.5)$ & $18.5(3.1)$ & $17.5(3.2)$ & $17.6(2.9)$ & $19.2(4.4)$ & $17.4(3.5)$ \\
\hline Fat mass $(\mathrm{kg})$ & $7.2(4.0)$ & $9.3(5.4)$ & $10.0(5.1)$ & $9.0(4.4)$ & $11.6(6.7)$ & $10.6(5.2)$ \\
\hline Height $(\mathrm{cm})$ & $146.9(8.1)$ & $149.8(10.4)$ & $145.2(8.5)$ & $147.5(9.1)$ & $151.6(8.1)$ & $145.6(8.2)$ \\
\hline Weight $(\mathrm{kg})$ & $39.8(9.6)$ & $48.5(15.1)$ & $39.2(10.8)$ & $42.5(11.3)$ & 49.1 (14.3) & $40.0(9.5)$ \\
\hline Body mass index $\left(\mathrm{kg} \mathrm{m}^{-2}\right)$ & $18.3(3.2)$ & $21.3(5.1)$ & $18.4(4.0)$ & $19.3(3.6)$ & $21.1(5.0)$ & $18.7(3.3)$ \\
\hline Fat mass $(\mathrm{kg})$ & $9.3(5.8)$ & $14.7(9.4)$ & $11.0(6.7)$ & $12.3(6.6)$ & $15.2(8.3)$ & $12.5(5.5)$ \\
\hline Fat-free mass $(\mathrm{kg})$ & $30.4(5.6)$ & $33.9(7.8)$ & $28.2(6.0)$ & $30.2(6.4)$ & $33.9(7.5)$ & $27.4(5.4)$ \\
\hline \multicolumn{7}{|l|}{$13-15$ years } \\
\hline$N$ & 62 & 29 & 31 & 81 & 36 & 35 \\
\hline Height $(\mathrm{cm})$ & $164.5(10.4)$ & $169.5(9.0)$ & $163.7(8.9)$ & $161.1(6.8)$ & $160.5(6.8)$ & $154.1(6.2)$ \\
\hline Weight (kg) & $53.4(11.4)$ & $62.9(16.6)$ & $54.3(16.7)$ & $56.9(12.7)$ & $54.4(10.8)$ & 44.5 (10.5) \\
\hline Body mass index $\left(\mathrm{kg} \mathrm{m}^{-2}\right)$ & $19.6(2.9)$ & $21.7(4.6)$ & $20.1(5.2)$ & $21.8(4.5)$ & $21.1(3.7)$ & $18.7(4.4)$ \\
\hline Fat mass $(\mathrm{kg})$ & $9.7(6.0)$ & $12.5(9.5)$ & $12.5(10.7)$ & $16.7(7.7)$ & $14.6(7.7)$ & $12.8(6.8)$ \\
\hline Fat-free mass $(\mathrm{kg})$ & $43.7(9.8)$ & $50.4(10.4)$ & $41.8(8.4)$ & $40.1(6.4)$ & $39.9(6.3)$ & $31.7(4.5)$ \\
\hline
\end{tabular}

in Figure 1. From the model, the optimal height power was consistently close to 5 between 4 and 12 years, but declined markedly from 13 years upwards; the interaction between log height and 1-year age groups was highly statistically significant $\left(P_{\text {Irtest }}<0.0001\right)$. In children aged $4-12$ years (with older children excluded), there was no evidence of interaction between log height and 1 -year age groups $\left(P_{\text {Irtest }}=0.87\right)$, suggesting that the height power was consistent across this slightly restricted age range. There was evidence of interaction between log height and Black African ethnicity $\left(P_{\text {Irtest }}=0.01\right)$, but no evidence of an interaction between log height and South Asian ethnicity $\left(P_{\text {lrtest }}=0.72\right)$; the estimated optimal height powers were 5.6 in Black Africans, 4.9 in White Europeans and 4.8 in South Asians. As it was crucial to have a constant height power across ethnic groups so that FMI was on the same scale, we investigated the use of these different height powers in the derivation of FMI. The absolute magnitude of the difference in FMl obtained using height powers between 5.6 or 4.8 was very small and the correlation between the FMI with height powers of 5.6 and 4.8 was very high ( $r=0.99)$ and (by definition) the ranking of individuals remained the same across the range of FMI. We therefore excluded the Black African interaction with log height from the model. There was no evidence of interaction between log height and sex $\left(P_{\text {Irtest }}=0.26\right)$. The overall height power needed to standardize FM for children aged 4-12 years was 5.05; for simplicity a power of 5.00 was used to derive FMI $\left(\mathrm{kg} \mathrm{m}^{-5}\right)$ for all children. Sensitivity analyses stratified by sex showed that the height powers needed for boys and girls were similar (Supplementary Figures S2 and S3), but model coefficients were less stable in sex-specific analyses.
Regression models relating $\mathrm{BMI}$ and $\mathrm{FMI}$

The forward stepwise procedure regressing BMI on FMl, ethnicity and age groups separately for each sex elicited the same order of selection of covariates in boys and girls. In addition to main effects (ethnicity and age groups), the strongest two-way interaction was between FMI and age group ( $P_{\text {lrtest }}<0.0001$ in boys and girls), followed by FMl and Black African ethnicity $\left(P_{\text {Irtest }}=0.004\right.$ in boys and $P_{\text {Irtest }}=0.003$ in girls). Other two-way interactions were not statistically significant at the 5\% level (Supplementary Table S3).

Graphical summaries of these modeled associations are presented in Figure 2 for boys and girls. The associations between BMI and FMl differed between ethnic groups. As the child's age increased, the BMI-FMI relationships became steeper for all ethnic groups. Both South Asian boys and girls had a consistently lower BMI for any given FMI than their White European counterparts for all three age groups; the BMI differences were constant at different FMls and different age groups. Black African children, compared with White Europeans, had a higher BMI for any given FMI. However, the differences between the Black Africans and White Europeans increased further at higher levels of FMI. (For example, the absolute differences in BMI between Black African and White European children for a given FMl of $2 \mathrm{~kg} \mathrm{~m}^{-5}, 4 \mathrm{~kg} \mathrm{~m}^{-5}$ and $6 \mathrm{~kg} \mathrm{~m}^{-5}$ were $1.3,2.2$ and $3.1 \mathrm{~kg} \mathrm{~m}^{-2}$, respectively) The corresponding regression coefficients (from which the figures were produced) are presented in Table 3. Normal plots of the residual did not show any departures from normality and there was no evidence of residual curvature when residuals were plotted against fitted values. The overall $R^{2}$ values indicated that the final models explained $74 \%$ of the variance in BMI for boys and $72 \%$ for girls. 


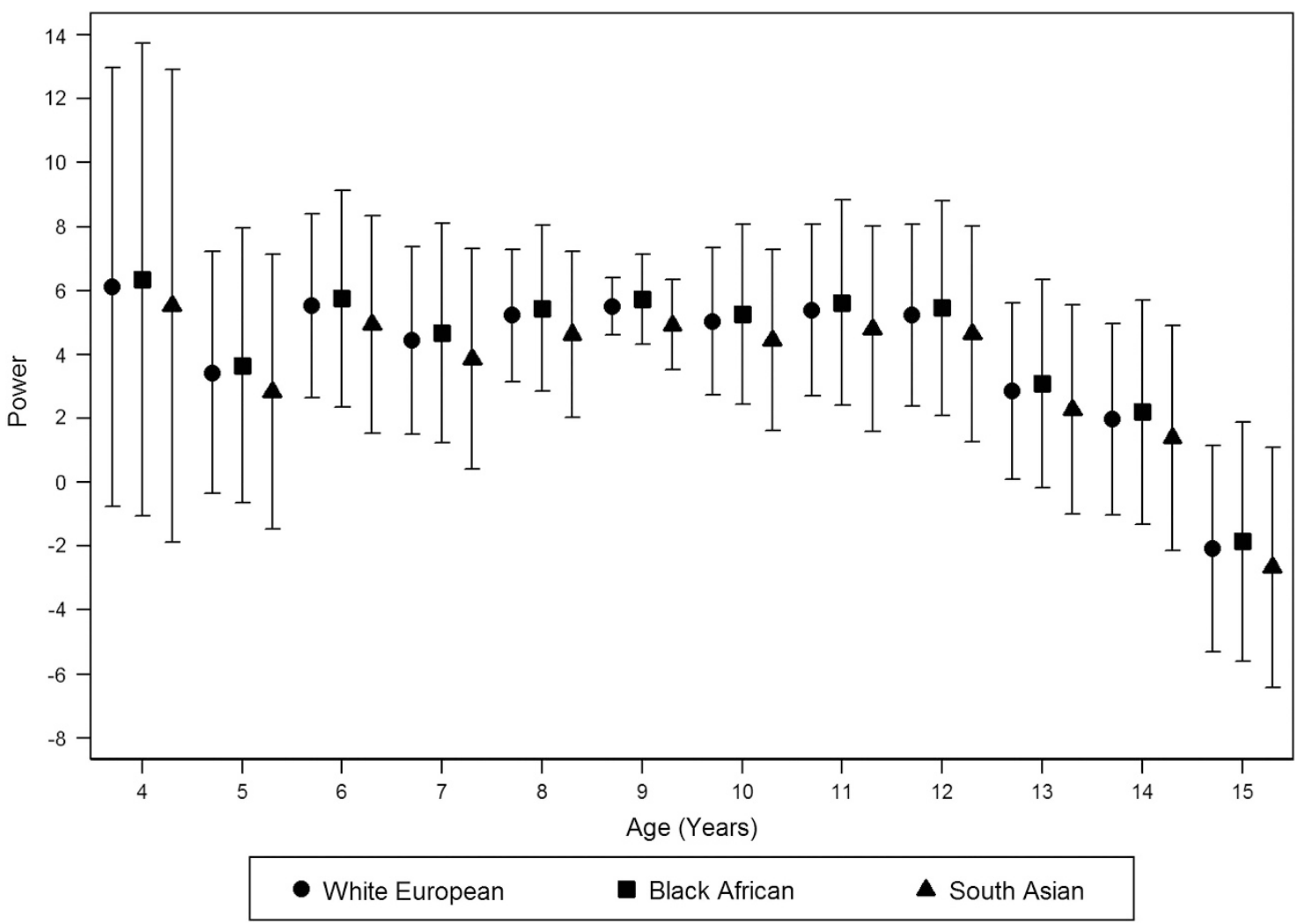

Figure 1. Optimal height powers for FMI in children 4-15 years by age (years) and ethnicity. Estimates are from regression analyses, including boys and girls, fitting log fat mass on log height with adjustment for age, ethnicity and sex and including interaction terms for age*log(height) and ethnicity*log(height).

\section{Ethnic-specific BMI adjustments}

To ensure that BMI related to FMI in the same way for children from all ethnic groups, BMI adjustments were derived using the coefficients from the final models in Table 3. Unadjusted and adjusted BMI values for the BMI range $13-25 \mathrm{~kg} \mathrm{~m}^{-2}$ are presented at $1.0 \mathrm{~kg} \mathrm{~m}^{-2}$ intervals for South Asian and Black African children (Table 1); unadjusted and adjusted BMI values and adjustment factors are presented for the full BMI range $\left(12-37 \mathrm{~kg} \mathrm{~m}^{-2}\right)$ at more precise increments of $0.1 \mathrm{~kg} \mathrm{~m}^{-2}$ for Black African children (Supplementary Tables S3 and S4). For South Asian children, BMI adjustments were positive and constant across age groups and FMI levels, $+1.12 \mathrm{~kg} \mathrm{~m}^{-2}(95 \%$ confidence interval $(\mathrm{Cl})$ : $0.83-1.41 \mathrm{~kg} \mathrm{~m}^{-2}$ ) for boys and $+1.07 \mathrm{~kg}\left(95 \% \mathrm{Cl}: 0.74-1.39 \mathrm{~kg} \mathrm{~m}^{-2}\right)$ for girls. In contrast, BMI adjustments for children of Black African origin were negative and depended on age group and FMI level (and indirectly on unadjusted BMI level) because of the interactions between Black African ethnicity and FMI and between FMI and age group. Adjustments were smaller in older age groups and increased with FMI levels, and thus with unadjusted BMI. Adjustments varied between $-0.13 \mathrm{~kg} \mathrm{~m}^{-2}$ (boys) and $-0.12 \mathrm{~kg} \mathrm{~m}^{-2}$ (girls) in 10-12 year olds with low unadjusted BMI values and $-5.52 \mathrm{~kg} \mathrm{~m}^{-2}$ (boys) and $-5.06 \mathrm{~kg} \mathrm{~m}^{-2}$ (girls) in 4-6 year olds with high unadjusted BMI values (Supplementary Table S4).

\section{DISCUSSION}

The aim of this research was to determine whether simple adjustments could be made to BMI values in South Asian and Black African children to provide BMI values with similar relations to total BF as those in White European children. In South Asian children aged between 4 and 12 years, single adjustment factors for South Asian boys and girls, adding $\sim 1.1 \mathrm{~kg} \mathrm{~m}^{-2}$ to the unadjusted $\mathrm{BMI}$ value irrespective of age and FMI, achieved this aim. For Black African children, negative adjustment factors achieved this aim, but these varied strongly with age and with FMI (and indirectly with unadjusted BMI); the smallest adjustment factors were applicable to older children with low BMI values and the largest to younger children with high BMI values.

\section{Consistency with previous reports}

The optimal FMI in children aged 4-12 years (FM per height ${ }^{5}$ ) was consistent with the results of earlier studies in 8-year-old ${ }^{22}$ and 910 -year-old children. ${ }^{10}$ In children aged 13 years and over, the optimal height power was markedly lower, reaching $\sim 2$ by 14 years of age. This is broadly consistent with a previous report suggesting an optimal height power of 2 for FMI in young adults. ${ }^{24}$ The low BMI levels in relation to FMI in South Asian children are consistent with previous reports in children based on bioimpedance, ${ }^{10}$ deuterium dilution ${ }^{11,25}$ and dual-energy X-ray absorptiometry $^{26}$ and with earlier studies in Asian adult populations. ${ }^{27}$ The high levels of BMI in relation to FMI in Black Africans are consistent with previous reports based on bioimpedance, ${ }^{10}$ deuterium dilution, ${ }^{11}$ dual-energy X-ray absorptiometry $^{26}$ and skinfold thickness measurements. ${ }^{28}$ As noted previously, ${ }^{10}$ these distinct ethnic patterns probably have different explanations, with the pattern in South Asian children reflecting the systematically higher FM and lower lean mass at a given BMI in children of approximately similar height. ${ }^{10,27}$ In contrast, the pattern in Black African children is likely to reflect their markedly greater height and different body shape. The positive BMI adjustments described here for South Asian children are consistent in direction with the lower BMI thresholds recommended for the definition of obesity in UK South Asian 

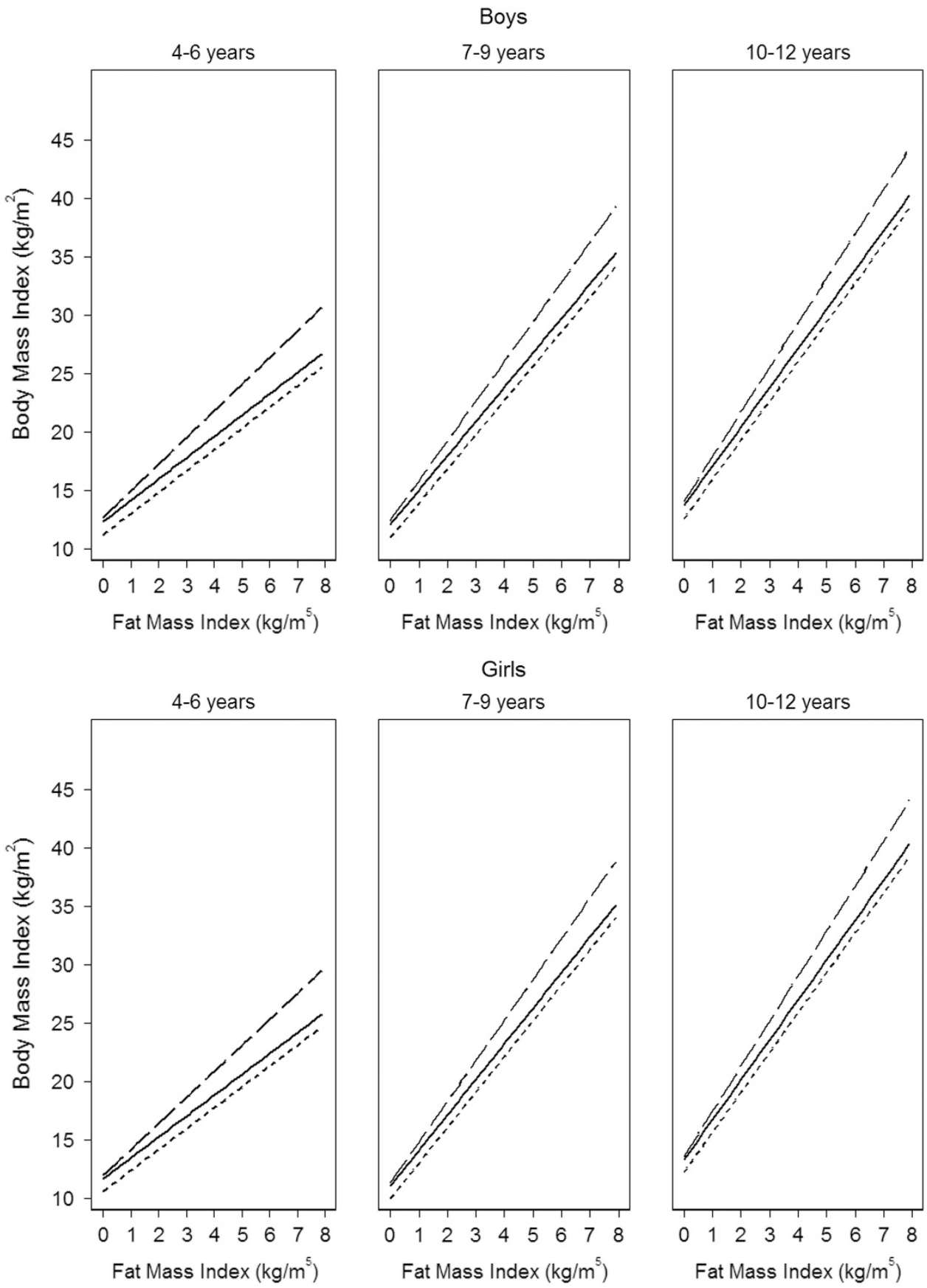

White Europeen - - Black African $\ldots . . . . . .$. South As ian

Figure 2. Relationships between BMI and FMI by age group for children of White European, Black African and South Asian origin. Body Mass Index based on best fitting linear regression models presented in Table 3.

adults based on equivalent type 2 diabetes risk. ${ }^{29,30}$ However, the size of the adjustments described here for South Asian children are markedly smaller than the adjustments in adult BMI thresholds, probably reflecting both the younger age group in the present study and different point of reference (total BF levels rather than type 2 diabetes risk levels).

\section{Strengths and limitations}

To our knowledge, this is the first analysis to use the deuterium dilution reference method to quantify BMI-FMI relationships in UK South Asian and Black African children across a relatively wide age range, to provide ethnic-specific BMI adjustments. BMI is a widely used marker of obesity and total BF in White European children; ${ }^{31}$ the deuterium dilution method provides accurate, safe and minimally invasive measurements of TBW (and FM) with an error of $<1 \% .^{32,33}$ The investigation was based on a pooled data resource including large numbers of UK children of South Asian and Black African origin as well as reference populations of White European children, allowing reasonably precise quantification of ethnic differences in the BMI-FMI relationship in the three main ethnic groups across a wide age range across which a single FMI could be applied (4-12 years), which importantly included both the younger ( $4-5$ years) and older (10-11 years) age groups of the 
Table 3. Coefficients for regression of body mass index on fat mass index adjusted for ethnicity and age group: by sex

\begin{tabular}{|c|c|c|c|c|c|c|}
\hline Variable & Coefficient & $95 \% \mathrm{Cl}$ & P-value & Coefficient & $95 \% \mathrm{Cl}$ & P-value \\
\hline Black African & 0.37 & $-0.25,0.99$ & 0.242 & 0.29 & $-0.41,1.00$ & 0.413 \\
\hline South Asian & -1.12 & $-1.41,-0.83$ & $<0.001$ & -1.07 & $-1.39,-0.74$ & $<0.001$ \\
\hline $7-9$ & & (Reference) & & & (Reference) & \\
\hline $10-12$ & 1.64 & $1.08,2.19$ & $<0.001$ & 2.26 & $1.52,3.01$ & $<0.001$ \\
\hline Black African $\times \mathrm{FMl}\left(\mathrm{kg} \mathrm{m}^{-5}\right)$ & 0.46 & $0.15,0.77$ & 0.004 & 0.44 & $0.14,0.73$ & 0.004 \\
\hline \multicolumn{7}{|l|}{$F M I\left(\mathrm{~kg} \mathrm{~m}^{-5}\right) \times$ age group } \\
\hline $\begin{array}{l}4-6 \\
7-9\end{array}$ & -1.12 & $\begin{array}{l}-1.59,-0.65 \\
\text { (Reference) }\end{array}$ & $<0.001$ & -1.26 & $\begin{array}{l}-1.72,-0.80 \\
\text { (Reference) }\end{array}$ & $<0.001$ \\
\hline
\end{tabular}

English National Child Measurement Programme, groups in which the need for accurate BMI interpretation is particularly pressing. However, this approach could not be applied to older children (13-15 years) who had a very different optimal FMI from that in 4-12 year olds. Although the study had limited ability to define separate adjustments for Indians, Pakistanis and Bangladeshis and for Black Africans of African and Caribbean descent, exploration of data for these separate ethnic subgroups suggested that there was no appreciable heterogeneity in BMI-FMI associations within the main South Asian and Black African groups, so that the adjustments provided should be widely applicable to UK South Asian and Black African children, who together account for a substantial proportion of the UK ethnic minority child population. However, the combined study resource included few children of other specific ethnic groups and children of mixed ethnicity; separate and specific studies would be needed to examine whether adjustments are needed in these other population groups. The generalizability of the adjustments developed for South Asian and Black African children outside the UK setting remains uncertain. It is possible that they are valid for children of South Asian and African origins in other Western countries, although this would require independent confirmation. We would however advise caution in the use of these adjustments in countries with majority South Asian or Black African populations, particularly when country-specific reference data are being used to define weight status.

The use of equivalent total body fatness as a reference point for deriving BMI adjustments in children is supported by its strong relationship to insulin resistance in childhood ${ }^{12}$ and by its greater contribution to explaining the higher levels of emerging insulin resistance and type 2 diabetes risk in childhood than simple markers of central and visceral adiposity. ${ }^{12,34}$ However, it is possible that using equivalent levels of visceral fat, which is particularly implicated in insulin resistance and type 2 diabetes risk in adults, ${ }^{35,36}$ as the basis for adjustments would have advantages over total BF. There is some evidence that South Asian adults have a greater proportional excess of visceral fat than total $\mathrm{BF}^{37}$ which would suggest that adjustments needed for South Asians could be larger than those indicated by equivalent total BF. However, this pattern has not been consistently reported in all studies $^{38}$ and accurate data on ethnic differences in visceral fat in
UK children are currently limited. It is also possible that South Asian children in particular have greater metabolic sensitivity to the effects of body fatness (including total BF) than White Europeans. $^{12}$ This would also raise the possibility that BMI adjustments for South Asian children should be larger than those based on equivalent total $\mathrm{BF}$, although again currently available data do not allow this possibility to be addressed in the formulation of adjustments.

Implications: potential for application in practice

We have shown that it is possible to derive adjusted BMI values for UK South Asian and Black African boys and girls, which are related to total BF (represented by FMI) in the same way as in White European children. For South Asians, the adjustments are positive and very simple, with increases of $\sim 1.1 \mathrm{~kg} \mathrm{~m}^{-2}$ both for boys and girls, irrespective of age and FMI. For Black Africans, the adjustments needed are negative and dependent on age group and FMI level, varying between -0.12 and $-5.52 \mathrm{~kg} \mathrm{~m}^{-2}$. Such adjustments should overcome the underestimation of total BF in South Asian children and its overestimation in Black African children, which arise when unadjusted BMI is used. ${ }^{10,12}$ These adjustments should be applicable for all UK children of South Asian and Black African origin; they may also be applicable in other settings but further evaluation will be needed. Once the relevant ethnic-specific adjustments are applied, it should then be possible to estimate weight status using the standard definitions used in the United Kingdom, including the UK 1990 growth reference and International Obesity Task Force classification systems. ${ }^{8,39}$ The use of this approach is therefore effectively using ethnic-specific assessment of BMI and it therefore departs from earlier recommendations, which have expressed caution or opposed ethnic-specific assessment of BMI in UK children, ${ }^{40,41}$ although such assessment is now advocated in adults. ${ }^{29,41}$ However, this approach, with initial BMI adjustment followed by the use of standard definitions for weight status relevant to the local population would be a simple process to implement and would avoid the need for new ethnic-specific BMl cutoffs for categorizing weight status in individual children, thereby reducing the scope for error and confusion.

Application of these adjustments should reduce the misclassification of individual children between normal and overweight- 
obese categories. It would however result in an appreciable increase in the prevalences of overweight-obesity in South Asian children, with a reduction in overweight-obesity prevalences in Black African children. For control of childhood overweightobesity and its consequences, this reduction in the under diagnosis of overweight and obesity in UK South Asian children would be particularly important; these children have higher levels of total BF than White Europeans ${ }^{10,12}$ and are at high long-term risk of type 2 diabetes and cardiovascular diseases. ${ }^{13,42}$ In addition, the application of these adjustments to population-based data on BMI in children, particularly in national surveys including the National Child Measurement Programme ${ }^{43}$ and the Health Survey for England ${ }^{14}$ should increase the accuracy with which population burdens of total BF, overweight and obesity in UK children from different ethnic groups are assessed.

The adjustments can be applied directly from the specific estimates provided above for South Asian children and for Black African children using the age and BMI-specific data presented for each $0.1 \mathrm{~kg} \mathrm{~m}^{-2}$ of BMI in Supplementary Table S3. Alternatively, a web-based calculator developed by the authors can be used, which links the calculation of adjusted BMI values (given the age, sex, weight, height and ethnicity of the individual child) to the weight status definitions (underweight, healthy, overweight, obese) provided by the UK 1990 growth reference reference populations (http://www.sgul.ac.uk/research/population-health/ bmiadjust).

\section{CONCLUSION}

The relationships between BMI and FMI differ between South Asians, Black Africans and White Europeans in children aged 4-12 years, so that BMI underestimates BF in South Asians and overestimates it in Black Africans. BMI adjustments have been calculated for UK South Asian and Black African children, so that adjusted BMI values are related to FMI in the same way as in White Europeans. These can be used to make the assessment of BF more accurate, both in individual UK children of South Asian and Black African origins and in the UK child population as a whole.

\section{CONFLICT OF INTEREST}

The authors declare no conflict of interest.

\section{ACKNOWLEDGEMENTS}

This work was supported by a project grant from the British Heart Foundation (Grant ref: $P G / 15 / 19 / 31336)$ and by the National Institute for Health Research (NIHR) Collaboration for Leadership in Applied Health Research and Care (CLAHRC) South London. Data collection in the ABCC, ELBI, RC and SLIC studies was funded by the British Heart Foundation (PG/11/42/28895), the BUPA Foundation (TBF-S09-019), Child Growth Foundation (GR 10/03) and the Wellcome Trust (WT094129MA). The views expressed are those of the authors and not necessarily those of the funding agencies, the NHS or the Department of Health. MF is supported by the Great Ormond Street Hospital Childrens' Charity (GOSHCC).

\section{AUTHOR CONTRIBUTIONS}

Study design-MTH, CMN, PHW, CGO, ARR, DGC, JCKW. Data collection—PHW, CMN, CGO, ASD, SL, JEW, DH, MSF, JCKW, ARR, DGC. Data analysis-MTH, ARR, DGC, CMN. Data interpretation-MTH, PHW, ARR, CGO, DGC, JCKW. Drafting manuscript-MTH, PHW, ARR. Critical evaluation and revision of manuscriptMTH, CMN, CGO, ASD, MTH, SL, JEW, DH, MSF, JCKW, ARR, DGC, PHW.

\section{REFERENCES}

1 Davies SC, Barlow J, Blackburn C, Blair M, Brooks F, Cheung R et al. Annual Report of the Chief Medical Officer 2012. Our children deserve better: prevention pays. Department of Health, 2013. Report No. Available at: https://www.gov.uk/gov
ernment/uploads/system/uploads/attachment_data/file/255237/2901304_CMO_ complete_low_res_accessible.pdf

2 Griffiths LJ, Parsons TJ, Hill AJ. Self-esteem and quality of life in obese children and adolescents: a systematic review. Int J Pediatr Obes 2010; 5: 282-304.

3 Owen CG, Whincup PH, Orfei L, Chou QA, Rudnicka AR, Wathern AK et al. Is body mass index before middle age related to coronary heart disease risk in later life? Evidence from observational studies. Int J Obes 2009; 33: 866-877.

4 The NS, Richardson AS, Gordon-Larsen P. Timing and duration of obesity in relation to diabetes: findings from an ethnically diverse, nationally representative sample. Diabetes Care 2013; 36: 865-872.

5 Wijga AH, Scholtens S, Bemelmans WJ, de Jongste JC, Kerkhof M, Schipper M et al. Comorbidities of obesity in school children: a cross-sectional study in the PIAMA birth cohort. BMC Public Health 2010; 10: 184.

6 Reilly JJ, Kelly J, Wilson DC. Accuracy of simple clinical and epidemiological definitions of childhood obesity: systematic review and evidence appraisal. Obes Rev 2010; 11: 645-655.

7 Cole TJ, Bellizzi MC, Flegal KM, Dietz WH. Establishing a standard definition for child overweight and obesity worldwide: international survey. BMJ 2000; 320: 1240-1243.

8 Cole TJ, Freeman JV, Preece MA. Body mass index reference curves for the UK, 1990. Arch Dis Child 1995; 73: 25-29.

9 Wells JC, Fewtrell MS. Measuring body composition. Arch Dis Child 2006; 91 : 612-617.

10 Nightingale CM, Rudnicka AR, Owen CG, Cook DG, Whincup PH. Patterns of body size and adiposity among UK children of South Asian, black African-Caribbean and white European origin: Child Heart and health Study in England (CHASE Study). Int J Epidemiol 2011; 40: 33-44.

11 Nightingale CM, Rudnicka AR, Owen CG, Donin AS, Newton SL, Furness CA et al. Are ethnic and gender specific equations needed to derive fat free mass from bioelectrical impedance in children of South asian, black African-Caribbean and White European origin? Results of the assessment of body composition in children study. PLoS One 2013; 8: e76426.

12 Nightingale CM, Rudnicka AR, Owen CG, Wells JC, Sattar N, Cook DG et al. Influence of adiposity on insulin resistance and glycemia markers among UK Children of South Asian, black African-Caribbean, and white European origin: child heart and health study in England. Diabetes Care 2013; 36: 1712-1719.

13 Whincup PH, Gilg JA, Papacosta O, Seymour C, Miller GJ, Alberti KG et al. Early evidence of ethnic differences in cardiovascular risk: cross sectional comparison of British South Asian and white children. BMJ 2002; 324: 635.

14 The Health and Social Care Information Centre. Health Survey for England 2004. The Health of Ethnic Minority Groups. The Health and Social Care Information Centre, London, UK, 2006.

15 Wild SH, Fischbacher C, Brock A, Griffiths C, Bhopal R. Mortality from all causes and circulatory disease by country of birth in England and Wales 2001-2003. J Public Health (Oxf) 2007; 29: 191-198.

16 Deurenberg P, Yap M, van Staveren WA. Body mass index and percent body fat: a meta analysis among different ethnic groups. Int J Obes Relat Metab Disord 1998; 22: 1164-1171.

17 Haroun D, Taylor SJ, Viner RM, Hayward RS, Darch TS, Eaton S et al. Validation of bioelectrical impedance analysis in adolescents across different ethnic groups. Obesity (Silver Spring) 2010; 18: 1252-1259.

18 Kirkby J, Bonner R, Lum S, Bates P, Morgan V, Strunk RC et al. Interpretation of pediatric lung function: impact of ethnicity. Pediatr Pulmonol 2013; 48: 20-26.

19 Wells JC, Williams JE, Chomtho S, Darch T, Grijalva-Eternod C, Kennedy K et al. Body-composition reference data for simple and reference techniques and a 4-component model: a new UK reference child. Am J Clin Nutr 2012; 96: 1316-1326.

20 Racette SB, Schoeller DA, Luke AH, Shay K, Hnilicka J, Kushner RF. Relative dilution spaces of ${ }^{2} \mathrm{H}$ - and ${ }^{18} \mathrm{O}$-labeled water in humans. Am J Physiol 1994; 267(Part 1): E585-E590.

21 Wells JC, Williams JE, Chomtho S, Darch T, Grijalva-Eternod C, Kennedy K et al. Pediatric reference data for lean tissue properties: density and hydration from age 5 to 20 y. Am J Clin Nutr 2010; 91: 610-618.

22 Wells JC, Cole TJ. Adjustment of fat-free mass and fat mass for height in children aged 8 y. Int J Obes Relat Metab Disord 2002; 26: 947-952.

23 Hocking RR. A Biometrics Invited Paper. The analysis and selection of variables in linear regression. Biometrics 1976; 32: 1-49.

24 Vanltallie TB, Yang MU, Heymsfield SB, Funk RC, Boileau RA. Height-normalized indices of the body's fat-free mass and fat mass: potentially useful indicators of nutritional status. Am J Clin Nutr 1990; 52: 953-959.

25 Lee S, Bountziouka V, Lum S, Stocks J, Bonner R, Naik M et al. Ethnic variability in body size, proportions and composition in children aged 5 to 11 years: is ethnicspecific calibration of bioelectrical impedance required? PLoS One 2014; 9: e113883. 
26 Shaw NJ, Crabtree NJ, Kibirige MS, Fordham JN. Ethnic and gender differences in body fat in British schoolchildren as measured by DXA. Arch Dis Child 2007; 92: 872-875.

27 World Health Organisation. Appropriate body-mass index for Asian populations and its implications for policy and intervention strategies. Lancet 2004; 363: 157-163.

28 Chinn S, Rona RJ, Gulliford MC, Hammond J. Weight-for-height in children aged 4-12 years. A new index compared to the normalized body mass index. Eur J Clin Nutr 1992; 46: 489-500.

29 Ntuk UE, Gill JM, Mackay DF, Sattar N, Pell JP. Ethnic-specific obesity cutoffs for diabetes risk: cross-sectional study of 490,288 UK biobank participants. Diabetes Care 2014; 37: 2500-2507.

30 Tillin T, Sattar N, Godsland IF, Hughes AD, Chaturvedi N, Forouhi NG. Ethnicityspecific obesity cut-points in the development of Type 2 diabetes-a prospective study including three ethnic groups in the United Kingdom. Diabet Med 2015; 32: 226-234.

31 Simmonds M, Burch J, Llewellyn A, Griffiths C, Yang H, Owen C et al. The use of measures of obesity in childhood for predicting obesity and the development of obesity-related diseases in adulthood: a systematic review and meta-analysis. Health Technol Assess (Winchester, England) 2015; 19: 1-336.

32 Wells JC, Fuller NJ, Dewit O, Fewtrell MS, Elia M, Cole TJ. Four-component model of body composition in children: density and hydration of fat-free mass and comparison with simpler models. Am J Clin Nutr 1999; 69: 904-912.

33 Deurenberg P, Yap M. The assessment of obesity: methods for measuring body fat and global prevalence of obesity. Baillieres Best Pract Res Clin Endocrinol Metab 1999; 13: 1-11.

34 Whincup PH, Nightingale CM, Owen CG, Rudnicka AR, Gibb I, McKay CM et al. Early emergence of ethnic differences in type 2 diabetes precursors in the UK: the Child Heart and Health Study in England (CHASE Study). PLoS Med 2010; 7: e1000263.

35 Hanley AJ, Wagenknecht LE, Norris JM, Bryer-Ash M, Chen YI, Anderson AM et al. Insulin resistance, beta cell dysfunction and visceral adiposity as predictors of incident diabetes: the Insulin Resistance Atherosclerosis Study (IRAS) Family study. Diabetologia 2009; 52: 2079-2086.
36 Kanaya AM, Wassel Fyr C, Vittinghoff E, Harris TB, Park SW, Goodpaster BH et al. Adipocytokines and incident diabetes mellitus in older adults: the independent effect of plasminogen activator inhibitor 1. Arch Intern Med 2006; 166: 350-356.

37 Lear SA, Humphries KH, Kohli S, Chockalingam A, Frohlich JJ, Birmingham CL. Visceral adipose tissue accumulation differs according to ethnic background: results of the Multicultural Community Health Assessment Trial (M-CHAT). Am J Clin Nutr 2007; 86: 353-359.

38 Park YW, Allison DB, Heymsfield SB, Gallagher D. Larger amounts of visceral adipose tissue in Asian Americans. Obes Res 2001; 9: 381-387.

39 Cole TJ, Lobstein T. Extended international (IOTF) body mass index cut-offs for thinness, overweight and obesity. Pediatr Obes 2012; 7: 284-294.

40 Viner RM, Cole TJ, Fry T, Gupta S, Kinra S, McCarthy D et al. Insufficient evidence to support separate BMI definitions for obesity in children and adolescents from South Asian ethnic groups in the UK. Int J Obes (2005) 2010; 34: 656-658.

41 National Institute for Health and Care Excellence. BMI: preventing ill health and premature death in black, Asian and other minority ethnic groups 2013. Available at: nice.org.uk/guidance/ph46.

42 Chowdhury TA, Grace C, Kopelman PG. Preventing diabetes in South Asians: too little action and too late. BMJ 2003; 327: 1059-1060.

43 The NHS Information Centre (Lifestyles Statistics). National child measurement programme: England 2009/10 school year. Report version 1.

(c) (i) $\odot$ This work is licensed under a Creative Commons Attributioncc. NonCommercial-NoDerivs 4.0 International License. The images or other third party material in this article are included in the article's Creative Commons license, unless indicated otherwise in the credit line; if the material is not included under the Creative Commons license, users will need to obtain permission from the license holder to reproduce the material. To view a copy of this license, visit http:// creativecommons.org/licenses/by-nc-nd/4.0/

(c) The Author(s) 2017

Supplementary Information accompanies this paper on International Journal of Obesity website (http://www.nature.com/ijo) 